\title{
An Investigation into Conversion of a Fleet of Plug-in-Electric Golf Carts into Solar Powered Vehicles Using Fuzzy Logic Control
}

\author{
Wafaa Saleh ${ }^{1,2, *, \dagger}$, Shekaina Justin ${ }^{1}$, Ghada Alsawah ${ }^{1,3}$, Areej Malibari ${ }^{4}$ and Maha M A Lashin ${ }^{1,5}$ \\ 1 College of Engineering, Princess Nourah Bint Abdulrahman University, Riyadh 84428, Saudi Arabia; \\ SJThambi@pnu.edu.sa (S.J.); gaalsawah@pnu.edu.sa (G.A.); mmlashin@pnu.edu.sa (M.M.A.L.) \\ 2 School of Engineering and The Built Environment, Edinburgh Napier University, Edinburgh EH10 5D, UK \\ 3 Mechanical Engineering Department, Higher Technological Institute, 10th of Ramadan City 44629, Egypt \\ 4 Department of Computer Science, Faculty of Computing and IT, King Abdulaziz University (KAU), \\ Jeddah 21589, Saudi Arabia; aamalibari1@kau.edu.sa \\ 5 Mechanical Department, Faculty of Engineering-Shoubra, Banha University, Banha 13518, Egypt \\ * Correspondence: wsshoukry@pnu.edu.sa or w.saleh@napier.ac.uk \\ + Visiting Professor.
}

check for updates

Citation: Saleh, W.; Justin, S.; Alsawah, G.; Malibari, A.; Lashin, M.M.A. An Investigation into Conversion of a Fleet of

Plug-in-Electric Golf Carts into Solar Powered Vehicles Using Fuzzy Logic Control. Energies 2021, 14, 5536. https://doi.org/10.3390/en14175536

Academic Editors: K.T. Chau and Tek Tjing Lie

Received: 15 June 2021

Accepted: 25 August 2021

Published: 4 September 2021

Publisher's Note: MDPI stays neutral with regard to jurisdictional claims in published maps and institutional affiliations.

Copyright: (c) 2021 by the authors. Licensee MDPI, Basel, Switzerland. This article is an open access article distributed under the terms and conditions of the Creative Commons Attribution (CC BY) license (https:/ / creativecommons.org/licenses/by/ $4.0 /)$.

\begin{abstract}
This paper presents an investigation factors that need to be considered in the design and selection of components for the conversion of a fleet of plug-in electric golf carts at Princess Nourah Bint Abdelrahman University, (PNU), Riyadh, Kingdom of Saudi Arabia (KSA), into solar power energy. Currently, the plug-in electric golf carts are powered by a set of deep-cycle lead-acid battery packs consisting of six units. Solar energy systems (photovoltaics and solar thermal) provide significant environmental benefits and opportunities over the traditional and conventional sources. Therefore, they can contribute positively to many aspects of the built environment and societies. There are many factors that affect the energy generated from the solar panel system. These include type and dimension of the solar panels, weight, speed, acceleration, and other characteristics of the used golf carts, and the energy efficiency of the solar energy system, as main factors that affect the green energy generated to operate the carts. The energy values needed to power the electric cart were calculated and optimized using traction energy calculation and optimized using a fuzzy logic analysis. The fuzzy logic system was developed to assess the impacts of varying dimensions of solar panel, vehicle speed, and weight on the energy generation. Initial calculations show that the replacement cost of the batteries can be up to approximately 75 percent of the operating cost. Together with the indirect cost benefits of achieving zero tail-pipe emission and the comfort of silent operation, the cost of operation using solar energy can be significant when compared with the cost of battery replacement. In order to achieve better efficiency, supercapacitors can be investigated to replace the conventional batteries. The use of fuzzy logic successfully facilitated the optimization of system operation conditions for best performance. In this study, fuzzy logic and calculated data were used as an optimization tool. Future work may be able to use fuzzy logic with experimental data to demonstrate feasibility of utilizing fuzzy logic systems to assess energy generation processes. Future investigations could also include investigation of other factors and methodologies, such as various types of batteries, supercapacitors, solar panels, and types of golf carts, together with different techniques of artificial intelligence to assess the optimum system specifications.
\end{abstract}

Keywords: golf carts; electric carts; solar energy; conversion of electric carts

\section{Introduction and Literature Review}

Electric vehicles have been recognized as a key technology in the mobility sector that are associated with reducing emissions, greenhouse gases, and fuel consumption. Therefore, electric carts are good candidates to demonstrate and begin the journey for achieving a much more sustainable mobility future. Small electric vehicles seem to be excellent options to achieve adaptation to solar energy initiatives in the transportation 
sector $[1,2]$. In order for this technology to achieve its target, it has to be powered by a source of renewable energy such as solar, wind, or natural gas. Solar energy technologies are fundamental components of a sustainable energy future since they provide clean, renewable, and a home energy source. In comparison to traditional energy sources, solar energy systems have significant environmental benefits. The development and operation of solar systems have considerable environmental consequences that have been demonstrated in literature [3].

Electromobility can contribute to more ecologically responsible, climate-friendly mobility. However, in terms of electric vehicles, it has not yet reached its full potential. There are two significant impediments to purchasing an electric automobile from the user's perspective: it is more expensive than a car with an internal combustion engine and it has a shorter range than a normal vehicle. Intermodal concepts based on electric shared vehicles can be a potential option because the total cost of ownership of the electric vehicles may be split among many users, and as part of the public transportation system, it can also serve as a supplement for local and long-distance travel [4].

The golf automobiles, in contrast, are created to be durable, dependable, and safe when used for long periods of time. There are many forms available for such cars (see the PNU golf cart picture, Figure 1). Solar panels, batteries, and electronics that can be used to power these types of golf carts have recently become more affordable, functional, and reliable, allowing for new and inventive uses. Various forms of solar-panel-powered electric carts have been seen in various studies. The solar powered golf cart can be used in many purposes including short distance travel where there is solar incidence, within campuses travel, and outside superstores to transport customers with mobility issues, elderly, and children [5].

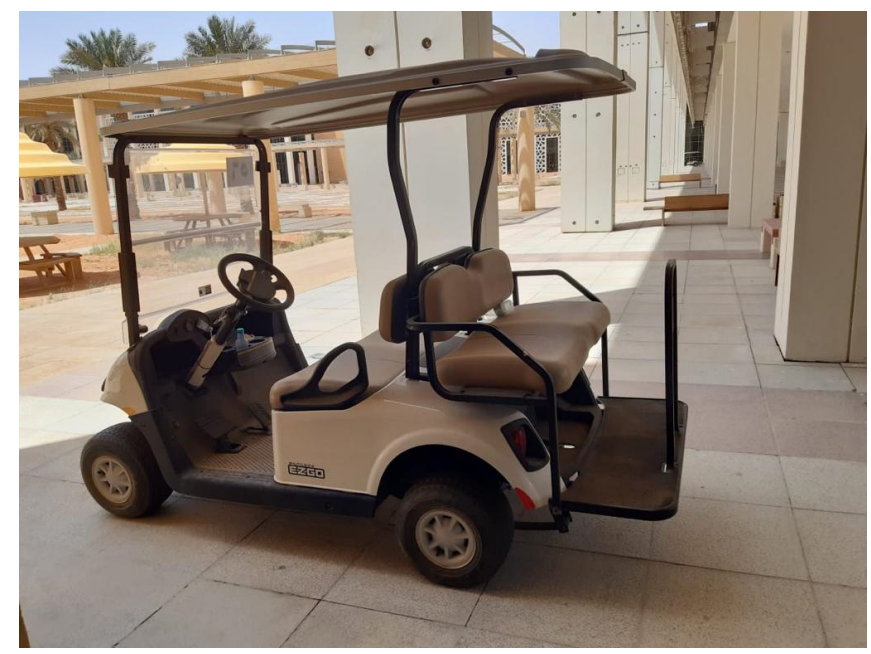

Figure 1. Princess Nourah Bint Abdelrahman University's golf cart.

In comparison to traditional energy sources, solar energy systems (photovoltaics and solar thermal) also provide significant environmental benefits, contributing to the long-term development of human evolution and well-being [6]. Solar energy is an abundant energy resource and the fastest growing renewable energy source in the world. In photovoltaic (PV) technology, many categories of solar panels have been produced and currently are used. Further development of similar products is also progressing in addition to the optimization techniques that contribute to cost reduction and energy efficiency [7].

The solar cell's efficiency is stated as the ratio of the calculated energy generation, the besieged direct current (DC) yield, and the actual alternating current (AC) yield generated [8]. This efficiency is often affected by factors such as dirt, sand, and snow together with other obstacles such as shade, etc. Electrical efficiency of the PV module (in this case, the higher the temperature of the panel, the lower the performance of the modules), also affects the system's overall efficiency [9]. 
In recent years, the market for solar energy has greatly expanded and further expansion is expected. This is due to the global interest in more renewable sources and because of the overall goal of achieving more sustainable societies.

The case of light electrical vehicles has been broadly studied by Keshri, Bertoluzzo, and Buja [10]. De Pinto et al. [11] investigated the allowance of the range of the EV via PV panels [11]. Kim et al. [12] investigated issues related to battery savings of the electrical vehicles while utilizing the vehicle's surface areas in order to optimize charging time [12], which is a new area of research [13]. The autonomy of the car showed an increase in both studies. Okedu [14] investigated the use of solar panels in hydrogen cars [14]. Other studies have focused on the PV integration and their applications [15]. Direct applications in buildings [16], PV parks [17] or on renewable-energy-based EV charging stations, specifically wind-based [18] and solar-based [19]. The available research is very scarce in innovative methods of solar integration, such as powering buggies, golf cars, and other options that can be used for sports or local transporting functions. This paper's objective is to explore whether or not such an investment in the PNU University's Golf carts would show potential saving in energy and provision of renewable energy.

Solar golf carts are mostly powered by a photovoltaic (PV) or thin film panel mounted on top of the existing roof, or using a PV panel as the roof itself (see Figure 1). A controller converts the sun's energy to charge the golf cart's supercapacitor bank. In terms of solar energy supply, the solar panels may well increase the distance the cart can travel on a single charge and hence can provide potential increased usage of these golf carts. In this paper, a case study is presented where we investigate the potential benefits of powering a university's fleet of battery-powered golf carts into solar energy power. The aim of the paper also is to briefly investigate the operation cost and its implications of adopting green energy to operate golf carts at Princess Nourah Bint Abdulrahman University (PNU) campus in Riyadh, Kingdom of Saudi Arabia, for transportation within the university, instead of using electric batteries. The paper is structured as follows: Section 1 provides an introduction and literature review of the study. The case study is presented in Section 2. System specification is overviewed in Section 3 with a discussion of the general specifications of the proposed main system and the operating characteristics. The methodology is presented in Section 4 where the calculations of energy needed to power the electric cart are presented. The fuzzy logic control system, which is used to assess optimum energy generation relative to the system specifications, is discussed in Section 5. Section 6 concludes the findings of the study and discusses future work.

\section{Case Study}

Princess Nourah Bint Abdelrahman University (PNU) in Riyadh, KSA, is the first all-female university in Riyadh that was established in 2006 with the aim of serving the development and progress of the Kingdom. Riyadh is $587 \mathrm{~m}$ above sea level. Riyadh has a desert climate. During the year, there is virtually no rainfall. According to Köppen and Geiger, this climate is classified as BWh. The average annual temperature is $26.2{ }^{\circ} \mathrm{Cl} 79.2^{\circ} \mathrm{F}$ in Riyadh. Precipitation averages about $66 \mathrm{~mm} / 2.6$ inch per year. The driest month is June, with $0 \mathrm{~mm} / 0.0$ inch of rainfall. Most of the precipitation here falls in April, averaging $14 \mathrm{~mm} / 0.6$ inch. The university's mission is distinguished by its leadership in education and scientific research. It contributes to establishing a knowledge-based economy with societal and global partnerships. The campus is 13 million square meters in size, with a maximum capacity of 60,000 students. The campus has 600 high-tech smart buildings, large-capacity student residencies, various models of faculty residence units, and three spacious, state-of-the-art recreation centers. In addition, it has preschools, primary schools, intermediate, and secondary schools. It also has an elegant central library, research centers, a university hospital, student support centers, student-accessible sport facilities, a convention center, and an automated metro system. Due to the large size of the campus, efficient means of transporting systems are in operation. These include an 
$11.5 \mathrm{~km}$ automated guideway metro system together with a fleet of 150 golf cars-100 plug-in-electric and 50 petrol engined that are used as a multipurpose utility vehicles.

The plug-in-electrics typically include $6-8$ batteries of $8-6$ volts/each. The recharging is usually carried out overnight at different centers located inside the university campus. Each car is charged every 2 to 3 days depending on the usage and the condition of its batteries. Batteries are replaced every 2 to 3 years. Therefore, the operating efficiency of the golf cars is rather limited in addition to the high cost associated with the operation of these cars. There are also operating cost implications regarding the golf cars used. In terms of the cost involved in operating the batteries, this is relatively high, as each unit costs about 850 to 900 SAR (226.7 to 240 USD) costing an average of around 4534-4800 USD on an annualized basis for the fleet. Assuming that each cart is operated on an average of about $2000 \mathrm{~km}$ annually, the cost of the battery works out to be about 0.12 USD per km of operation. Even after considering the indirect cost benefits accrued on account of the zero tail-pipe emission and the comfort of silent operation, the cost of operation is quite undesirable. Moreover, the cost of operating and maintaining the charging centers are also involved, though they are not as high when compared with the cost of battery replacement.

\section{System Specifications}

The annual solar incidence at PNU location is about $2350 \mathrm{kWh}$, translating into a daily mean solar incidence of $6.44 \mathrm{kWh}$ [20]. There are only a few days in the year when the solar incidence is low due to cloud cover or when the angle of incidence is relatively positive for energy generation.

The PNU golf cart roof has a dimension of $2 \mathrm{~m} \times 1 \mathrm{~m}$. The cart roof is the location where harvesting of solar energy is undertaken. When the surface area is increased, the generated energy is increased. Table 1 shows the estimated energy generated by different dimensions and conversion efficiency ranges as found in the market, which have been based on published findings [20-23].

Table 1. The energy generated by different dimensions and conversion efficiency ranges as found in the market.

\begin{tabular}{ccccc}
\hline \multirow{2}{*}{ Solar Panel Dimension } & \multicolumn{4}{c}{ Energy Generated (kWh) } \\
\cline { 2 - 5 } & $\boldsymbol{\eta} \mathbf{1 5 \%}$ & $\boldsymbol{\eta}=\mathbf{1 8 \%}$ & $\boldsymbol{\eta}=\mathbf{2 1 \%}$ & $\boldsymbol{\eta}=\mathbf{2 4 \%}$ \\
\hline $1.8 \mathrm{~m} \times 0.9 \mathrm{~m}$ & 1.56 & 1.88 & 2.19 & 2.50 \\
$2.0 \mathrm{~m} \times 1.0 \mathrm{~m}$ & 1.9 & 2.32 & 2.70 & 3.09 \\
$2.5 \mathrm{~m} \times 1.2 \mathrm{~m}$ & 2.9 & 3.48 & 4.06 & 4.64 \\
\hline
\end{tabular}

For example, with a $2.0 \mathrm{~m} \times 1.0 \mathrm{~m}$ area of the roof covered with solar panel, the energy generated by a panel with $24 \%$ efficiency should work out to be $2.7 \mathrm{kWh}$ per day on an average, which is more than sufficient to meet the daily usage for the golf cart, as illustrated later.

When the area of the roof is increased, thereby increasing the panel area, and when the conversion efficiency of the solar panel used is high, the supercapacitor capacity can be decreased. This will help in reducing the cost and mass of the supercapacitor module. The increase in mass of solar panel is relatively low when compared with increase in mass of the supercapacitor on account of higher capacity.

We need to compare this energy with the energy produced from the battery pack fitted in the golf cart, which consists of either 6 units of $8 \mathrm{~V}-170$ Ah or 8 units of $6 \mathrm{~V}-170 \mathrm{Ah}$ deep-cycle lead-acid batteries connected in series totaling an energy capacity of $8.16 \mathrm{kWh}$. The net energy available to be discharged from the battery pack is about $4 \mathrm{kWh}$. Based on the available data, as $4 \mathrm{kWh}$ energy is utilized over a period of 2 to 3 days, the mean daily distance covered is in the range of about 10 to $15 \mathrm{~km}$. These data indicate the optimum capacity needed for the supercapacitor bank. 
As the charging would be done with solar PV panel installed on the roof of the cart, and as the supercapacitor could be fully discharged, a supercapacitor bank with a capacity of 1.5 to $2 \mathrm{kWh}$ is considered optimal to meet the current usage. In any unlikely event of a mismatch between solar incidence and demand for transport, for example, recharging $1 \mathrm{kWh}$ using a $100 \mathrm{kWh}$ charger would take no more than $50 \mathrm{~s}$.

The parameters that can be considered for selecting the solar panels are mean efficiency, efficiency variance with respect to temperature, type of the solar panels and their connections to withstand stress and vibrations, mass per unit area of the panel, cost of the panel per unit area for panels fabricated as per specified dimensions, cost per unit area of readily available panels, and flexibility of the panel [20-23]. Panels designed exclusively for transport applications or panels fabricated with similar design should be considered. The solar panels suitable for this application are thin-film rolled panels, perovskite single junction and multijunction panels, thick-film panels and semiflexible silicon panels $[24,25]$. It should be noted, however, that the commercial availability of some of these panels may not be fully guaranteed. Since there are many factors involved, the investigation in this paper focuses on the solar panel types (or dimension, in this case), speed of the golf cars, and energy efficiency as main factors that affect the green energy generated to operate the carts. The energy values needed to power the electric cart was calculated and assessed using traction energy calculation and optimized using fuzzy logic analysis. The fuzzy logic system was developed to assess the impacts of varying dimensions of solar panel, speed of vehicle, and weight on the energy generation.

\section{Methodology Traction Energy Calculation}

Vehicle acceleration, maximum velocity, and range are the main parameters that affect traction energy calculations. In order to consider these forces, it is therefore required to include the force due to rolling resistance, the aerodynamic force, the acceleration force, and the rotational acceleration force [26]. The impact of driver behavior is represented in the acceleration force while the impact of the passengers should be included in the total weight of the vehicle. For this analysis and for simplification, the energy required for operating the golf cart is assumed to be the sum of two components only, as given below:

1. Rolling resistance force

2. Aerodynamic drag force

Assuming that the mean speed of the golf cart is $25 \mathrm{~km} / \mathrm{h}$, mass is $500 \mathrm{~kg}$, air density $1.2 \mathrm{~kg} / \mathrm{m}^{3}$, and the energy conversion efficiency of the cart $\eta=0.75$, the electricity consumption is calculated as follows (Equation (1)):

$$
E_{25}=\frac{v\left(c \cdot m \cdot g+0.5 c_{d} \cdot p \cdot A \cdot v^{2}\right)}{\eta}
$$

where $c=0.06$ (rolling resistance coefficient)

$m=500 \mathrm{~kg}$ (mass of the cart)

$g=9.81 \mathrm{~m} \mathrm{~s}^{-2}$ (gravitational acceleration)

$c_{d}=0.7$ (aerodynamic drag coefficient)

$p=1.2 \mathrm{~kg} \mathrm{~m}^{-3}$ (density of air)

$v=6.94 \mathrm{~m} \mathrm{~s}^{-1}$ (velocity of cart)

$\eta=0.75$ (energy conversion efficient of the cart)

$A=1.5 \mathrm{~m}^{2}$ (frontal area)

$E_{25}=3238.67 \mathrm{Wh}$

This is equal to $3.238 \mathrm{kWh}$. On the other hand, the energy generation obtained in Section 3 above is $2.7 \mathrm{kWh}$. Given that the speed of the golf cart is much lower than $6.94 \mathrm{~ms}^{-1}$, the energy generated should be sufficient to run the cart. For comparison, Table 2 shows the level of energy need, energy consumption, and energy generation from solar panels. From the table, it appears that while the theoretical value for energy requirement 
per day is $3.238 \mathrm{kWh}$, the actual value needed to run the cart is slightly lower; a value of $2.66 \mathrm{kWh}$ seems sufficient.

Table 2. Summary of golf cart energy requirement and energy generation from batteries and solar panels.

\begin{tabular}{ccc}
\hline $\begin{array}{c}\text { Energy Need } \\
\text { kWh }\end{array}$ & $\begin{array}{c}\text { Energy Generation from Battery } \\
\text { Set kWh (over 2-3 Days) }\end{array}$ & $\begin{array}{c}\text { Energy Generation from Solar } \\
\text { Panel System kWh }\end{array}$ \\
\hline 3.238 & $4.0(1.33 /$ day $)$ & 2.7 \\
\hline
\end{tabular}

Other than that, the factors that can be investigated in this case that impact electricity consumption are vehicle speed, solar panel dimensions, and energy efficiency factors. In the section below, a fuzzy logic control system is developed to investigate impacts of various values of these factors on the energy production. Fuzzy logic controllers (FLCs) have the following advantages over the conventional controllers: they are easily developed and processed using very simple software, they can cover a broader range of operating conditions, and they are more readily adaptable in natural language terms. It should be noted, however, that it is possible to use other conventional methods.

\section{Fuzzy Logic Control System}

In managing complicated situations, fuzzy logic systems are effective prediction tools. These models or groups are mathematical representations of the ambiguity and hazy information. They are capable of distinguishing, expressing, explaining, and operating this ambiguous and imprecise information. They can be programmed to calculate a difference between data sets by emulating human thinking processes [27]. Because there is no "standard" mathematical model available or one that can be derived from physical laws for effectively modeling pedestrians' crossing behavior, fuzzy logic is clearly effective in this type of inquiry. Furthermore, because fuzzy systems were first offered to represent human decision-making by weighing rules, it appears sensible to utilize them to simulate human behavior. Fuzzy logic has a wide range of applications, including transportation (for example, [28-31]). In comparison to other industries, however, transportation has a considerable dearth of fuzzy logic system applications. The membership functions are an important aspect of fuzzy logic analysis. The membership functions can take a variety of shapes including triangular, trapezoidal, and Gaussian [32,33] for assessing the efficiency of estimation of various forms. Because of their simplicity and ease of computation, the triangular and trapezoidal membership functions are frequently used in various applications. As a result, adopting a triangle form as a first step in any research is reasonable. Other forms can be utilized if the system's performance is not adequate.

A nonlinear translation of input data sets to scalar output data is a fuzzy logic system [27]. As shown in Figure 2, the fundamental mechanisms of a fuzzy system are a fuzzifier and a defuzzifier, if-then rules, and an inference engine. The use of a fuzzy logic system has the advantage of being able to manage challenges involving imprecise and partial data. They can also simulate arbitrary or sophisticated nonlinear functions.

\subsection{Fuzzy Logic Analysis}

The values of electricity required for driving golf cars used as transportation inside PNU are affected by cart speed and solar panel area. The mathematical equation for calculating the electricity needed to power the golf carts and to confirm a fuzzy logic control system was designed and implemented for the car working variables (cart speed and roof area), which enabled a prediction of the electrical power required for driving the car.

The fuzzy logic system was developed using the traction energy calculations presented earlier in the paper. The membership function of fuzzy logic is a fundamental component of a fuzzy logic system and the most crucial stage in fuzzy set construction. The membership function controls the fuzziness feature of a fuzzy set. The only requirement for a membership function is that it must fluctuate between 0 and 1 . Because of their simplicity 
and ease of calculation, triangle and trapezoidal membership functions are frequently used in various applications, as opposed to other function types such as bell, sigmoidal, asymmetric, LR, and Gaussian, which may need more sophisticated mathematical procedures. In addition, defining a triangular and trapezoidal membership function requires fewer data. In our instance, it might be most appropriate to utilize a triangle shape.

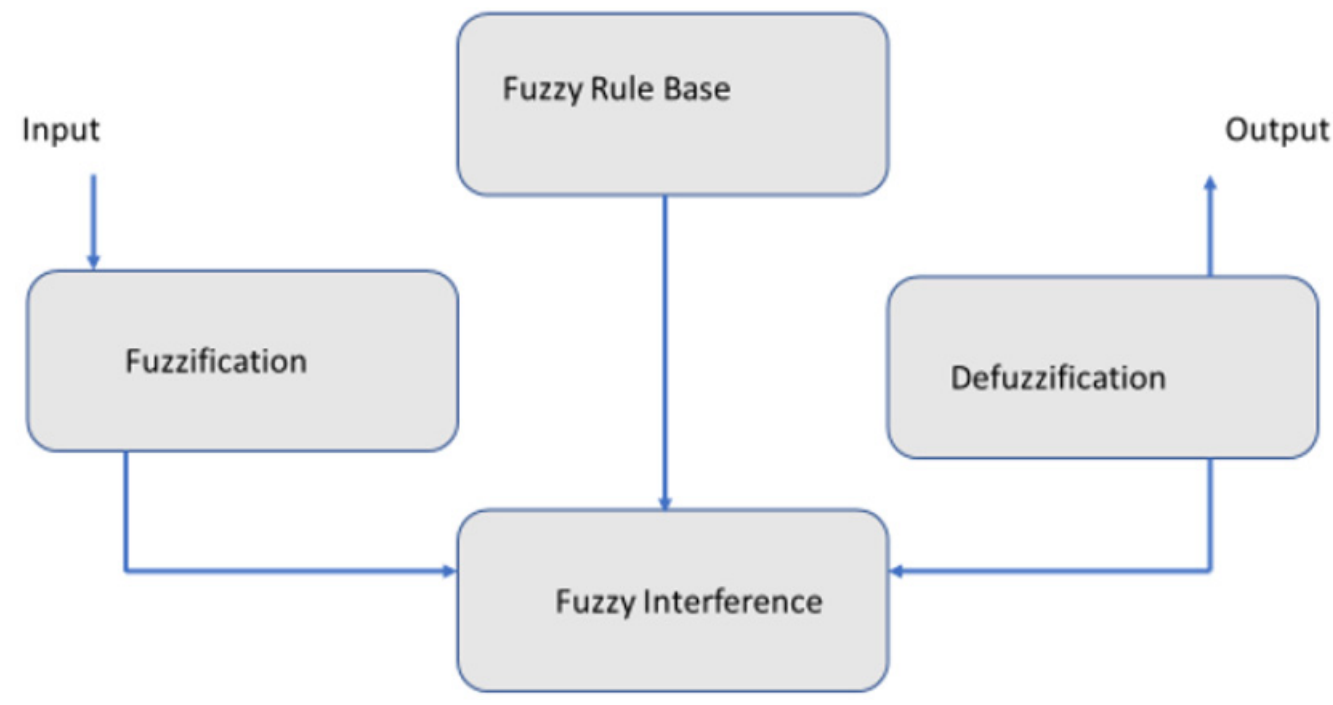

Figure 2. Architecture of the fuzzy system.

Table 3 lists the names and input and output variables that correspond to the parameter ranges with the triangular membership functions. Three parameters were included to define the input variables for building and implementing fuzzy logic systems (low, medium, and high).

Table 3. Levels and name of inputs (triangular membership function) used and output variables and range values.

\begin{tabular}{cccc}
\hline \multirow{2}{*}{ Variables } & \multicolumn{3}{c}{ Inputs } \\
\cline { 2 - 4 } & Low & Medium & High \\
\hline Cart velocity $\mathrm{km} / \mathrm{h}$ & $22.5-27.5$ & $27.5-32.5$ & $32.5-37.5$ \\
\hline Solar panel dimension $\mathrm{m}^{2}$ & $1.5-1.74$ & $1.74-2.26$ & $2.26-4.26$ \\
\hline Energy conversion efficiency\% & $14-16$ & $16-20$ & $20-24$ \\
\hline
\end{tabular}

\subsection{Detection of Electrical Power Using the Fuzzy System}

The fuzzy system procedure that is used in this study follows Mendel's (1995) methodology, which consists of three steps:

1. Fuzzification process;

2. Inference process based on if-then rules;

3. Defuzzification process.

The first step is to fuzzify the data, which can be done by using fuzzy linguistic variables and membership functions to convert the input data to a fuzzy set. The inference procedure is then carried out using if-then rules. Finally, the defuzzification stage is accomplished, and fuzzy outputs are crisped using membership functions (Figure 3). Each of these steps is further illustrated below. 


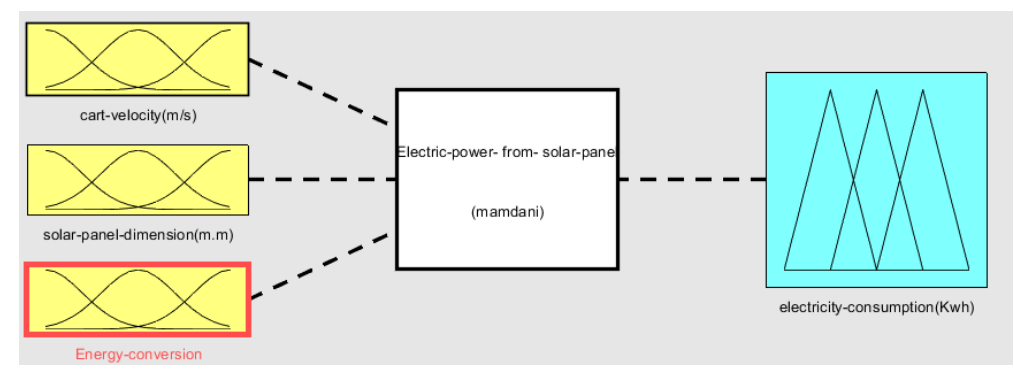

Figure 3. Fuzzy logic system for electric power from solar panel.

\subsection{Fuzzification Process}

The fuzzy logic system's first stage is the fuzzification process. Fuzzy linguistic variables and membership functions are used to turn the input data into a fuzzy set at this stage. Three to seven language variables are commonly used to muddle the input and output components. It would be inefficient to use less than three values since it would be difficult to discriminate the output after fuzzy inference [29-34]. The number of fuzzy rules employed would become more complicated if there were more than seven.

The membership function in the fuzzification process is built in this case utilizing three parameters a, b, c for each input and output variable, representing low, medium, and high values of each of the inputs, with variable ranges shown in Table 3. The estimating toolkit that comes with MATLAB was used. The $\mathrm{z}$ coordinates of the three vertices in a fuzzy set $\mathrm{L}$ are represented by the triangle membership function, which is determined by the three parameters $a, b$, and c. (a and $c$ are the lower and upper boundaries, where membership degree is $0 ; \mathrm{b}$ is the center, where membership degree is 1 ).

$$
\mu_{A}(z)=\left\{\begin{array}{c}
0 \text { if } z \leq a \\
\frac{z-a}{b-a} \text { if } a \leq z \leq b \\
\frac{c-z}{c-b} \text { if } b \leq z \leq c \\
0 \text { if } z \geq c
\end{array}\right.
$$

The real-time data can then be matched with the fuzzy model established, and a mathematical explanation for selecting a determined value for a rule, such as sum-ofsquared-error minimization or any other applicable rule, can be provided using this toolkit. For operating a golf automobile, a fuzzy system is employed to determine the values of electrical power obtained from a solar panel. Low, medium, or high membership functions are available for all variables. This was done for all input and output variables in the same way (Table 3). The values and structure of inputs, outputs, and critical gap values for the three adopted ranges are shown in Table 1 and Figure 4.

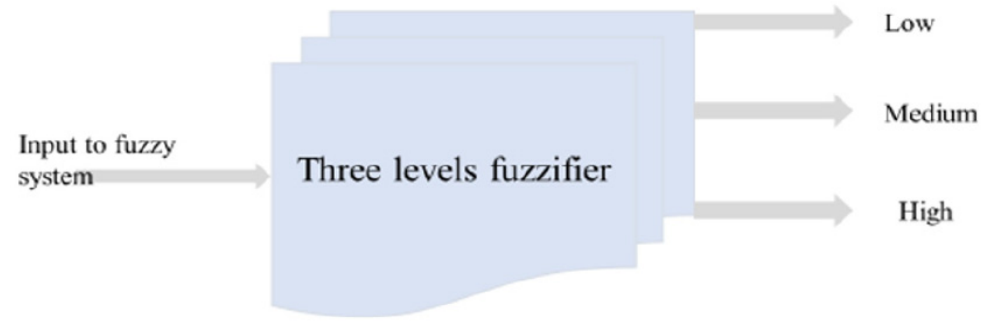

Figure 4. Fuzzification process of electric power from the solar panel fuzzy logic system.

Figure 5a-d depicts the fuzzy logic system's three levels of inputs and outputs, along with the membership function ranges for the inputs and outputs, respectively. The membership functions used are of the triangular type, as seen in the fuzzy system's inputs and outputs. As previously stated, triangle membership functions are one of several options for determining the best values for the introduced criteria. While the simplicity of this division is apparent, it does not exclude the construction of additional partitions that are 
optimal in terms of the specified requirements for the input and output interface while also performing better in terms of processing block optimization.

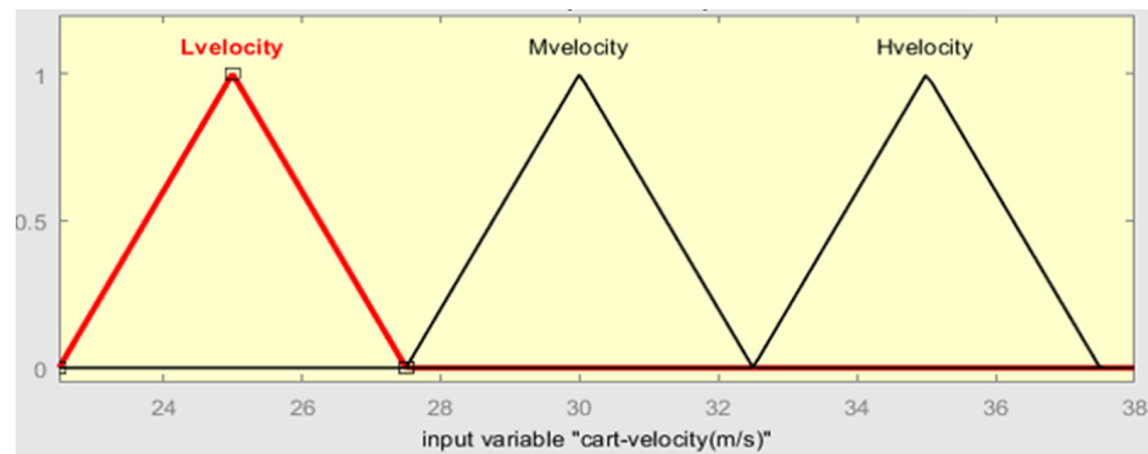

(a)

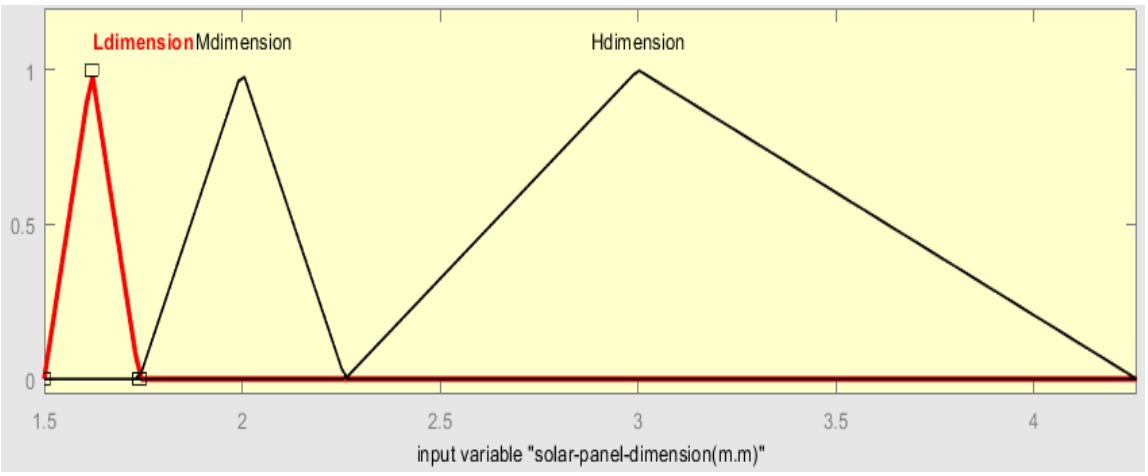

(b)

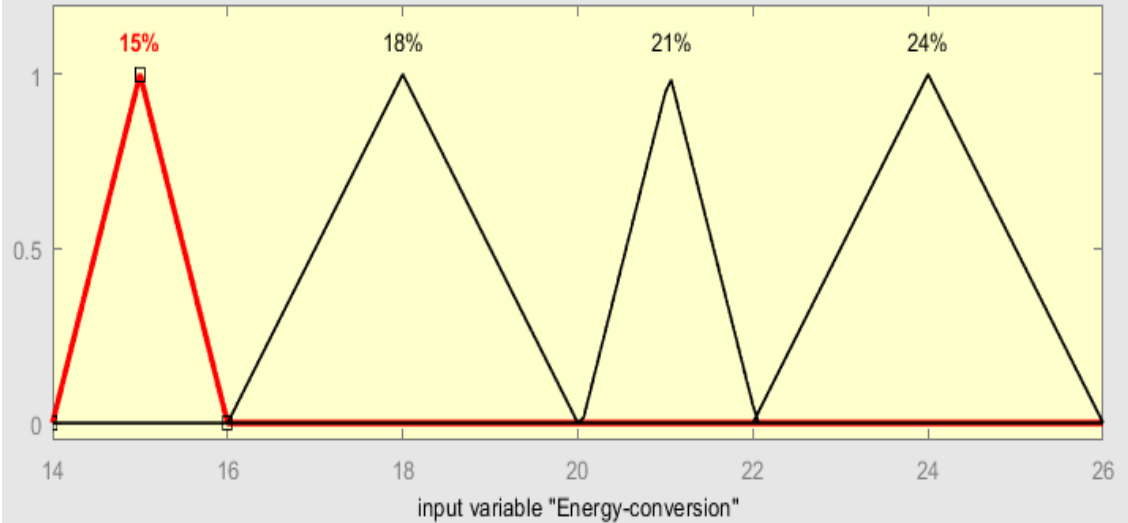

(c)

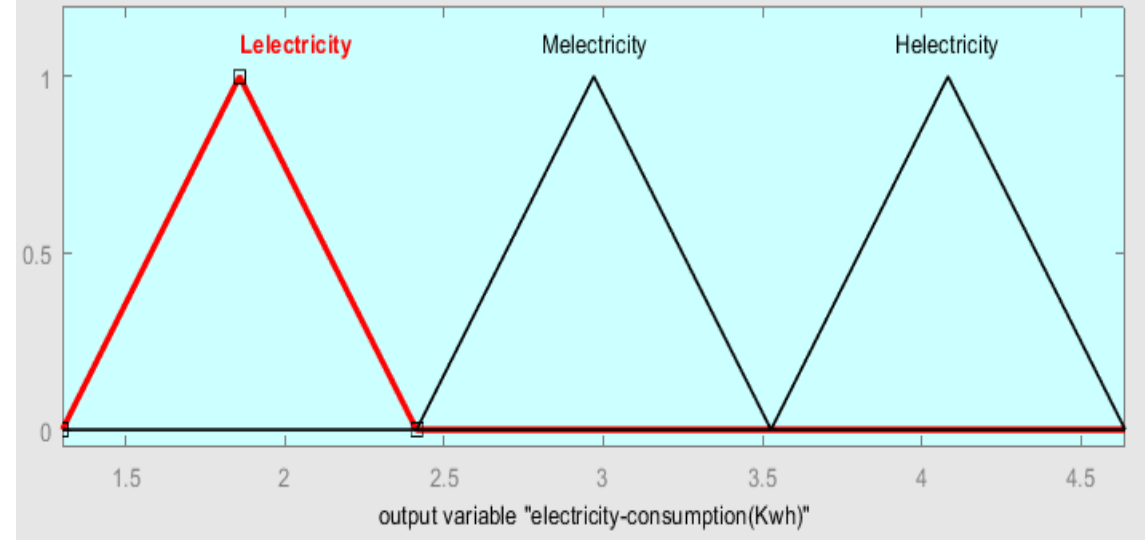

(d)

Figure 5. Low, medium, and high values for inputs (a-c) and output (d). 


\subsection{Inference Process Based on If-Then Rules}

Inference operations are carried out utilizing linguistic if-then rules to determine the relationships between the input and output variables, which are based on a wide range of if-then rules. The linguistic fuzzy logic control system that is a part of the suggested fuzzy control or fuzzy decision step, generates the if-then rules. Table 4 lists some of the if-then rules that were employed in this inquiry. To cover all possible outcomes, fifteen if-then rules were employed in this research.

Table 4. A few examples of if-then rules that were used as part of the proposed fuzzy decision.

\section{Fuzzy Rules (If-Then Rules)-Relationship between Inputs and Outputs}

If (cart-velocity (m/s) is Lvelocity) and (solar-panel-dimension (m.m) is Ldimension) and (energy-conversion-efficiency-of-the-cart is $15 \%$ ) then (electricity-consumption $(\mathrm{kWh})$ is Lelectricity)

If (cart-velocity (m/s) is Lvelocity) and (solar-panel-dimension (m.m) is Mdimension) and (energy-conversion-efficiency-of-the-cart is $21 \%$ ) then (electricity-consumption $(\mathrm{kWh})$ is Helectricity)

If (cart-velocity (m/s) is Lvelocity) and (solar-panel-dimension (m.m) is Hdimension) and (energy-conversion-efficiency-of-the-cart is $24 \%$ ) then (electricity-consumption $(\mathrm{kWh})$ is Helectricity)

\subsection{Defuzzification Step}

The process of defuzzification is the final step in the optimization process using a fuzzy control system. The defuzzification procedure is based on each person's membership function and the computation of their decisions. If the performance does not meet the assessment criteria, some fuzzy rules will need to be adjusted and the test performed again. Using the same inputs (Table 3), a graphical illustration of the defuzzification process is shown in Figures 4 and 6 and Table 5, which illustrate the outcomes of the fuzzy system.

1

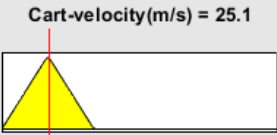

2

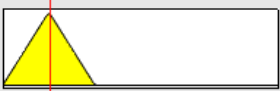

3

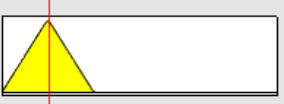

4

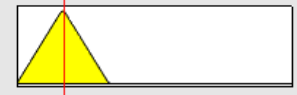

5

6
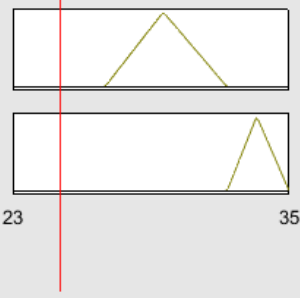

Solar-panel-dimension $(m \cdot m)=3.26$
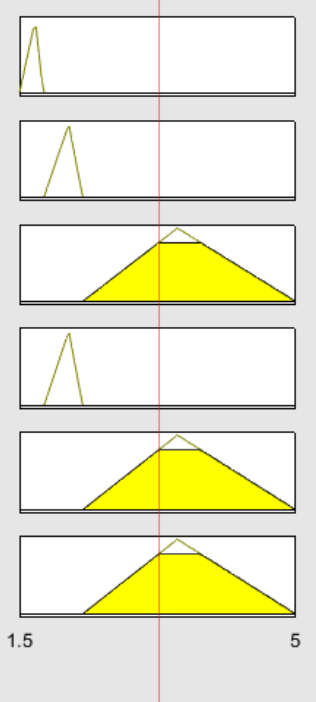

Energy-conversion $=22.3$
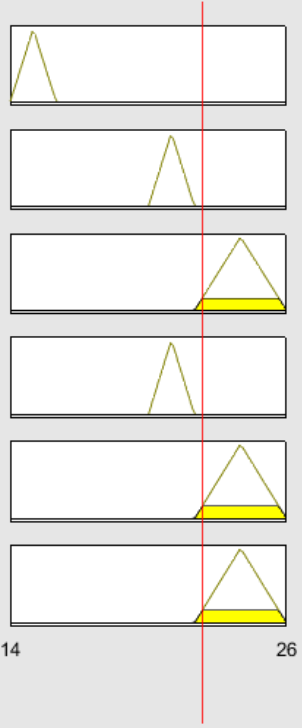

Electricity-consumption $(K w h)=4.12$
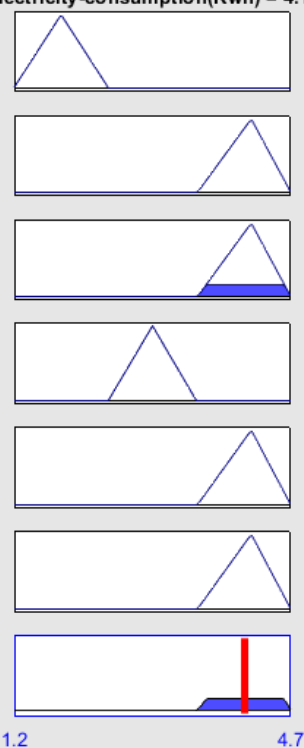

Figure 6. Results of electric power from the solar panel fuzzy logic system. 
Table 5. Levels and name of outputs obtained from the fuzzy logic system and input values.

\begin{tabular}{cccc}
\hline \multirow{2}{*}{ Variables } & \multicolumn{3}{c}{ Inputs } \\
\cline { 2 - 4 } & Low & Medium & High \\
\hline Cart velocity $\mathrm{km} / \mathrm{h}$ & $22.5-27.5$ & $27.5-32.5$ & $32.5-37.5$ \\
\hline Solar panel dimension $\mathrm{m}^{2}$ & $1.5-1.74$ & $1.74-2.26$ & $2.26-4.26$ \\
\hline Energy conversion efficiency \% & $14-16$ & $16-20$ & $20-24$ \\
\hline Variables & & Output & \\
\cline { 2 - 4 } & Low & Medium & High \\
\hline PV Electricity production $\mathbf{k W h}$ & $\mathbf{1 . 3 - 2 . 4 1 3}$ & $\mathbf{2 . 4 2 - 3 . 5 3}$ & $\mathbf{3 . 5 2 - 4 . 6 4}$ \\
\hline
\end{tabular}

The results from fuzzy analysis (Figure 5 and Table 6) show that the minimum PV electrical energy production is achieved at lower values of cart speed and energy conversion efficiency factors. The maximum PV electricity energy production obtained is $4.17 \mathrm{kWh}$ and this was acquired with maximum input parameter values.

Table 6. Output results from the proposed fuzzy system.

\begin{tabular}{ccccc}
\hline \multirow{2}{*}{ Values } & \multicolumn{3}{c}{ Inputs } & Output \\
\cline { 2 - 5 } & Cart Velocity & $\begin{array}{c}\text { Solar Panel } \\
\text { Dimension }\end{array}$ & $\begin{array}{c}\text { Energy } \\
\text { Conversion }\end{array}$ & $\begin{array}{c}\text { PV Electricity } \\
\text { Production }\end{array}$ \\
\hline Minimum value & 23.1 & 2.04 & 14.8 & 1.86 \\
\hline Maximum value & 25.2 & 3.28 & 21.2 & 4.17 \\
\hline
\end{tabular}

\section{Conclusions}

The aim of this paper is to investigate an optimum energy generation methodology that can be implemented using a renewable energy source. The energy generation is needed to power a set of golf cars at PNU campus in Riyadh, KSA. It is proposed therefore, to adopt a green energy system rather than using electricity from the grid to charge the batteries that are used to power the golf carts. As Riyadh, KSA, consistently receives very good solar radiation, calculations were carried out to assess the energy requirement to power these vehicles and to determine if the area of the roof is sufficient to meet mean daily energy requirements.

Based on the mean utilization derived from the charging interval, initial investigations show that the replacement cost of the battery is about 75 percent of the operating cost.

Then, based on the theoretical energy production for traction and the charging interval, the mean distance covered daily was calculated. Assuming that each cart is making an average of about $2000 \mathrm{~km}$ annually, the cost of the battery is assumed to be 0.12 United States Dollar (USD) per km of operation.

If the proposed adoption of green energy is implemented, the annual expenditure incurred in the replacement of batteries would be totally considered as initial and running cost savings. In addition, the energy consumed in charging the batteries is saved, which results in green-energy environmental benefits leading to sustainability of resources and lower emissions resulting from less conventional electricity production. In addition, there will be savings on consumables such as acid and distilled water. Moreover, there will be savings in labor spent on recharging, maintaining, and replacing vehicles. Using fuzzy logic facilitated the optimization of system operation conditions for best performance, taking into account three variables: cart velocity, solar panel dimensions, and energy conversion efficiency. Other variables are also possible. Future investigations could include investigating various types of batteries, capacitors, solar panels, and types of golf carts, together with using different techniques of analytical and artificial intelligence to assess the optimum system specifications. In this case, fuzzy logic facilitated the optimization of 
system operation conditions for best performance based on the three variables identified. These could be changed, and the optimization conditions could also be altered to include different conditions.

It is further suggested that research should examine the reduction of selected pollutant emissions, lower traditional fuel consumption, and extent of decreased operating cost when PV panels are used to power golf carts. Further research into alternative fuels and appropriateness for their use in this case is also recommended.

Author Contributions: Conceptualization, W.S. and S.J.; methodology, all; software, M.M.A.L. and A.M.; validation, W.S., S.J. and G.A.; formal analysis, S.J. and M.M.A.L.; investigation, W.S. and G.A. resources, A.M. and W.S.; data curation, M.M.A.L. and S.J. writing-original draft preparation, W.S. and S.J.; writing-review and editing, all; visualization, all; supervision, W.S.; project administration, W.S.; funding acquisition College of Engineering, PNU. All authors have read and agreed to the published version of the manuscript.

Funding: The APC was funded by DSR and PNU.

Institutional Review Board Statement: Not applicable.

Acknowledgments: This research project was funded by the Deanship of Scientific Research, Princess Nourah bint Abdulrahman University, through the Program of Research Project Funding after Publication, grant No (41-PRFA-P-39).

Conflicts of Interest: The authors declare no conflict of interest.

\section{References}

1. Helmers, E.; Marx, P. Electric cars: Technical characteristics and environmental impacts. Environ. Sci. Eur. 2012, 24, 1-15. Available online: http:/ / www.enveurope.com/content/24/1/14 (accessed on 25 August 2021). [CrossRef]

2. Kobayashi, S.; Plotkin, S.; Ribeiro, S.K. Energy efficiency technologies for road vehicles. Energy Effic. 2009, 2, 125-137. [CrossRef]

3. Gunerhan, H.; Hepbasli, A.; Giresunlu, U. Environmental Impacts from the Solar Energy Systems. Energy Sources Part A Recovery Util. Environ. Eff. 2008, 31, 131-138. [CrossRef]

4. Wappelhorst, S.; Sauer, M.; Hinkeldein, D.; Bocherding, A.; Glaß, T. Potential of electric carsharing in urban and rural areas. Transp. Res. Procedia 2014, 4, 374-386. [CrossRef]

5. Milani, R.; Couto, L.C.; Soria, R.; Szklo, A.; Lucena, A.F. Promoting social development in developing countries through solar thermal power plants. J. Clean. Prod. 2020, 246, 119072. [CrossRef]

6. Tsoutsos, T.; Frantzeskaki, N.; Gekas, V. Environmental Impacts from the Solar Energy Technologies. Energy Policy 2005, 33, 289-296. [CrossRef]

7. Nižetić, S.; Papadopoulos, A.M.; Giama, E. Comprehensive analysis and general economic-environmental evaluation of cooling techniques for photovoltaic panels, part I: Passive cooling techniques. Energy Convers. Manag. 2017, 149, 334-354. [CrossRef]

8. Peters, I.M.; Liu, H.; Reindl, T.; Buonassisi, T. An energy yield calculator for solar cells worldwide. In Proceedings of the 2018 IEEE 7th World Conference on Photovoltaic Energy Conversion, WCPEC 2018-A Joint Conference of 45th IEEE PVSC, 28th PVSEC and 34th EU PVSEC, Berlin, Germany, 10-15 June 2018; pp. 453-454.

9. Zhang, H.L.; Van Gerven, T.; Baeyens, J.; Degrève, J. Photovoltaics: Reviewing the European feed-in-tariffs and changing PV efficiencies and costs. Sci. World J. 2014, 2014, 404913. [CrossRef] [PubMed]

10. Keshri, R.; Bertoluzzo, M.; Buja, G. Integration of a photovoltaic panel with an electric city car. Electr. Power Compon. Syst. 2014, 42, 481-495. [CrossRef]

11. De Pinto, S.; Lu, Q.; Camocardi, P.; Chatzikomis, C.; Sorniotti, A.; Ragonese, D.; Iuzzolino, G.; Perlo, P.; Lekakou, C. Electric vehicle driving range extension using photovoltaic panels. In Proceedings of the 2016 IEEE Vehicle Power and Propulsion Conference, VPPC, Hangzhou, China, 19 December 2016; pp. 1-6.

12. Kim, J.; Wang, Y.; Pedram, M.; Chang, N. Fast photovoltaic array reconfiguration for partial solar powered vehicles. In Proceedings of the 2014 International Symposium on Low Power Electronics and Design, ISLPED '14, La Jolla, CA, USA, 11 August 2014; pp. 357-362.

13. Gupta, K.; Achathuparambil Narayanankutty, R.; Sundaramoorthy, K.; Sankar, A. Optimal location identification for aggregated charging of electric vehicles in solar photovoltaic powered microgrids with reduced distribution losses. Energy Sources Part A Recovery Util. Environ. Eff. 2020, 1-16. [CrossRef]

14. Okedu, K.E. Integrated renewable energy system: Intelligent adjustable solar panel and hydrogen cars. Renew. Energy Sources Appl. Emerg. Technol. 2016, 17, 131-158.

15. Koroneos, C.; Nanaki, E.; Xydis, G. Air Conditioning Systems and Their Applicability-An Exergy Approach, Resources, Conservation and Recycling; Elsevier: Amsterdam, The Netherlands, 2010; Volume 55, pp. 74-82. [CrossRef] 
16. Saber, E.M.; Lee, S.E.; Manthapuri, S.; Yi, W.; Deb, C. PV (photovoltaics) performance evaluation and simulation-based energy yield prediction for tropical buildings. Energy 2014, 71, 588-595. [CrossRef]

17. Xydis, G. A techno-economic and spatial analysis for the optimal planning of wind energy in Kythira Island, Greece. Int. J. Prod. Econ. 2013, 146, 440-452. [CrossRef]

18. Xydis, G.; Nanaki, E. Wind energy based electric vehicle charging stations sitting. A GIS/wind resource assessment approach. Challenges 2015, 6, 258-270. [CrossRef]

19. Mouli, G.R.C.; Leendertse, M.; Prasanth, V.; Bauer, P.; Silvester, S.; van de Geer, S.; Zeman, M. Economic and CO 2 emission benefits of a solar powered electric vehicle charging station for workplaces in the Netherlands. In Proceedings of the 2016 IEEE Transportation Electrification Conference and Expo(ITEC), Dearborn, MI, USA, 27-29 June 2016.

20. Zell, E.; Gasim, S.; Wilcox, S.; Katamoura, S.; Stoffel, T.; Shibli, H.; Engel-Cox, J.; Al Subie, M. Assessment of solar radiation resources in Saudi Arabia. Solar Energy 2015, 119, 422-438. [CrossRef]

21. Li, X.; Li, P.; Wu, Z.; Luo, D.; Yu, H.Y.; Lu, Z.H. Review and Perspective of Materials for Flexible Solar Cells, Materials Reports: Energy; Elsevier: London, UK, 2020.

22. Zinaddinov, M.; Milshtein, S. Design of light-weight solar panels. In Proceedings of the 2019 IEEE 46th Photovoltaic Specialists Conference (PVSC), Chicago, IL, USA, 16-21 June 2019.

23. IRENA. Future of Solar Photovoltaic: Deployment, Investment, Technology, Grid Integration and Socio-Economic Aspects (A Global Energy Transformation: Paper); International Renewable Energy Agency: Abu Dhabi, United Arab Emirates, 2019.

24. Abderrezek, M.; Djeghlal, M.E. Comparative study on $\mathrm{Cu}_{2} \mathrm{ZnSn}(\mathrm{S}, \mathrm{Se})_{4}$ based thin film solar cell performances by adding various back surface field (BSF) layers. Chin. J. Phys. 2020, 63, 231-239.

25. Rokonuzzaman, M.; Hossam-E-Haider, M. Design and Implementation of Maximum Power Point Tracking Solar Charge Controller. Presented at the 2016 3rd International Conference on Electrical Engineering and Information Communication Technology (ICEEICT), Dhaka, Bangladesh, 22-24 September 2016.

26. Shaikh, M. Design of an Electric Golf Cart with Batteries \& Solar Panel for 6 Seat Capacity. Int. Res. J. Eng. Technol. 2019, 6, 2103-2122.

27. Ansari, A. The Basics of Fuzzy Logic: A Tutorial Review, Computer Education; Computer Education Group: Stamford, UK, 1998; Volume 88, pp. 5-9.

28. Chai, C.; Shi, X.; Wong, Y.D.; Er, M.J.; Gwee, E.T.M. Fuzzy logic-based observation and evaluation of pedestrians' behavioral patterns by age and gender. Transp. Res. Part F Traffic Psychol. Behav. 2016, 40, 104-118. [CrossRef]

29. Islam, N.; Haider, M.; Uddin, M.B. Fuzzy logic enhanced speed control system of a VSI-fed three phase induction motor. In Proceedings of the 2nd International Conference on Electrical and Electronics Engineering, Rome, Italy, 22-23 July 2019; pp. 296-301.

30. Demiroz, Y.I.; Onelcin, P.; Alver, Y. Illegal road crossing behavior of pedestrians at overpass locations: Factors affecting gap acceptance, crossing times and overpass use. Accid. Anal. Prev. 2015, 80, 220-228. [CrossRef] [PubMed]

31. Saady, G.E.; Sharaf, A.M.; Makky, A.; Sherbiny, M.K.; Mohamed, G. Ahigh performance induction motor drive system using fuzzy logic controller. In Proceedings of the 7th Mediterranean Electrotechnical Conference, Antalya, Turkey, 12-14 April 1994; Volume 3, pp. 1058-1061.

32. Wu, B.; Yan, X.; Wang, Y.; Soares, C.G. Selection of maritime safety control options for NUC ships using a hybrid group decision-making approach. Saf. Sci. 2016, 88, 108-122. [CrossRef]

33. Hsien-Chung, W. The optimality conditions for optimisation problems with fuzzy-values objective functions. J. Optim. 2008, 57, 473-489.

34. Goedtel, A.; da Silva, I.N.; Serni, P.J.A. Load torque identification in induction motor using neural networks technique. Electr. Power Syst. Res. 2007, 77, 35-45. [CrossRef] 